\title{
Light interception efficiency analysis based on three-dimensional peach canopy models
}

Liyu Tang*, Can Hou, Hongyu Huang, Chongcheng Chen, Jie Zou, Ding Lin

(National Engineering Research Center of Geospatial Information Technology, Key Laboratory of Spatial Data Mining \& Information Sharing of MOE, Fuzhou University, Fuzhou, 350002, China)

\begin{abstract}
Light interception capability is a critical factorc affecting the growth, development, fruit yield and quality of fruit trees; thus, it is beneficial to cultivate optimal canopy types with high light interception efficiency. In this study, we present a quantitative method of analyzing light interception by tree canopies based on a virtual plant model. A detailed three-dimensional(3D) peach model with a natural growth shape was reconstructed and then the branches in the model were pruned to generate canopies with an open center form. These models were used to calculate the light interception and corresponding net photosynthesis. A solar radiation transfer model was used to determine the radiation intensity at the top of the canopy, and a ray tracing algorithm and turtle algorithm were utilized to simulate the spatial distribution of direct and diffuse radiation, respectively, in the tree canopy and obtain the photosynthetically active radiation (PAR) for each leaf. In the final step, we applied the photosynthesis model to calculate the canopy net photosynthetic rate. To compare the light interception efficiency among various plant canopy shapes, the net production rate at the whole-canopy scale and the average net photosynthetic rate per unit leaf area were calculated. The simulation results showed that peach canopies with an open center form provided better results compared with canopies with a natural form in terms of light penetration and air ventilation. Our method supports quantitative analysis of light interception and use efficiency for different types of canopy architectures at each time step and for individual leaf units. The approach was implemented in the interactive parametric individual 3D tree modeling software ParaTree. The extended ParaTree software is useful for fruit tree management applications because it provides an intuitive tool that can assist in tree pruning and design for ideal canopy architecture types.
\end{abstract}

Key words: virtual plant; pruning; light interception; canopy architecture; photosynthesis; peach

\section{Introduction}

The morphological architecture of fruit tree canopies affects light interception and distribution within the canopy. Light interception plays an important role in certain plant physiological processes, such as photosynthesis and transpiration; therefore, it affects the growth, development, fruit yield and quality of the plant (Da Silva et al., 2014; Génard et al., 2000; Wang et al., 2009). In the field of fruit tree cultivation and management, favorable light penetration and wind ventilation conditions in tree canopies are achieved through pruning and training systems; thus, the quality and quantity of flowers and fruits can be improved(Willaume et al., 2004). Canopy interception of photosynthetically active radiation (PAR) is an important parameter that

\footnotetext{
* Corresponding author Tel.: +86-13799421872

E-mail address: tangly@fzu.edu.cn
} 
can be used to indicate how much PAR is reaching the elements of canopy(Cieslak et al., 2008) and help analyze what is the optimal canopy form for certain fruit trees.

Traditionally there are two types of methods to study canopy interception of solar radiation. One is by field measurement; the other is through mathematic modeling. Field measurement can be used effectively, but it is time-consuming and labor expensive. And it is difficult to obtain data with high spatial and temporal resolution. The method is suitable for lower trees with small canopy as it is difficult to measure trees that are large and tall. The mathematic modeling method simulates how the radiation is transferred within plant canopy and makes some assumption or simplification approximately the canopy architecture. Radiation transfer model and geometric models of canopy architecture are used to estimate light interception in canopy. The canopy architecture model is represented as a turbid medium. This type of canopy models mostly assumes that leaves are small and random uniformly distributed in the canopy(Barillot et al., 2011) with leaf angle distribution function being ellipsoidal(Annandale et al., 2004) or spherical distribution(Rakocevic et al., 2000). The real architecture complexity is greatly reduced. Therefore, the approach is just a simplified approximation of real tree. In the medium, the radiation attenuation can be estimated by the Beer-Lambert law. Then, the light interception is usually calculated according to leaf area index (LAI) and extinction coefficient(Annandale et al., 2004). Although these methods provide a good estimation of total light interception within the canopy, they did not take the effects of local light intensity and canopy heterogeneity on the light interception into consideration (Da Silva et al., 2014; Sarlikioti et al., 2011; Vos et al., 2009). To provide a better understanding of light distribution within canopies, new approaches have emerged that utilize detailed organ-based 3D models(Génard et al., 2000). 3D organ models can be reconstructed from data obtained by 3D digitizing instruments that perform measurements in the field or by software (e.g., L-system). Although the model is static and not applied to describe the plant development, it is useful for studying light distribution in the canopy(Iio et al., 2011; Vos et al., 2009); therefore, it is a good tool for assisting in the design of canopy types with high light interception(Su et al., 2008). Virtual plants can describe quantitatively accurate plant topology, geometry and organ position. Plant organs can be represented at every small individual 3D unit, and radiation transmission and interception among the units can be simulated with ray tracing or radiosity algorithms. Studies have used virtual plant approaches, and the light environment in the greenhouse and light interception on cut rose can be simulated to predict the local (per leaf) light absorption and photosynthesis(Buck-Sorlin et al., 2011). Han et al.( 2012) and Da Silva et al.(2014) combined the 3D apple modeling tool MAppleT and light interception model VPlants to investigate the influence of the architectural parameters of apple trees on the light interception efficiency. In addition, the light interception efficiency of young Cunninghamia lanceolata canopies was calculated for growth simulation(Tang et al., 2012).

The photosynthesis characteristics and light interception capacity of peach trees have been studied and analyzed primarily by adopting traditional field measurement methods, and these analyses have produced meaningful observations and conclusions. In a study of the annual variation of photosynthesis rates of peaches with open center forms and spindle forms, the peak photosynthesis rate occurred in September(Wang et al., 2009). In young nectarine training systems, trees with the central leader form had the greatest light interception capabilities at the early stage of canopy formation(Gao et al., 2006). Virtual plant modeling has also been applied to perform growth simulations and light interception analysis of peach trees. L-PEACH is a 
functional-structural model that is based on L-system software, and it can simulate multiple-year tree growth. Tree growth has been described in a schematic or semi-realistic manner(Allen et al., 2007). A 3D peach model was constructed(Sonohat et al., 2006) by combining partially digitized tree structures with reconstruction rules for non-digitized organs. The tree model reconstruction approach provides a detailed 3D model for light interception analysis. 3D tree models have been used to simulate the photosynthesis of peaches according to the amount of direct and diffuse radiation(Génard et al., 2000). QualiTree integrates simple light interception and physiological process models to help design innovative horticultural best practices(Mirás-Avalos et al., 2011).

The objective of this study is to develop a quantitative analysis approach and tool for designing tree canopy types with high light interception efficiency based on virtual plants. We analyzed the light distribution in the peach canopy of varied forms and then evaluated the light interception. The interactive parametric individual 3D tree modeling tool ParaTree(Lin et al., 2011; Lin et al., 2012; Tang et al., 2011) was extended by integrating the radiation transfer model and photosynthesis model.

\section{Materials and methods}

\subsection{D peach tree model reconstruction}

Detailed 3D architecture models provide the foundation for canopy radiation transfer and distribution simulations, and the precision of the 3D model has a direct impact on the accuracy of the radiation simulation. Because leaves are the main plant organ that absorbs solar PAR, they are described explicitly. We focused on analyzing light interception in peach canopies with a natural form and open center form. The 3D canopy models were constructed using the interactive parametric individual 3D tree modeling tool ParaTree(Lin et al., 2011; Lin et al., 2012; Tang et al., 2011). In ParaTree, a tree model is composed of a main trunk, several branch levels, leaves and/or other organs. We used a set of parameters to describe the structure and shape characteristics of these components, and the parameters included the geometric and topological properties and morphological information. ParaTree allows user to build tree models for various species at different growth stages or different phenological phases by interactively modifying parameters. Moreover, this software can simulate branch pruning by interactively picking and editing a stem segment for constructing models of all types of canopy forms. Thus, ParaTree is a useful tool for designing canopy forms.

The key steps for generating a 3D peach tree model are listed as follows. (1) Acquire the morphological parameters, such as the tree height, crown width and branch length of the natural form and open center form peach trees through field observation and literatures study. For the trunk, the parameters include the basal diameter of the trunk, changes in diameter, length of the trunk and number of branch levels. The branch parameters are grouped based on the branch level, and the parameters for each level primarily include the distribution range of each branch level from the father stem, initial diameter of each branch level, changes in diameters, length of each branch level, etc. The leaf parameters include the size (width and length), shape, location, and distribution density. (2) Create a trunk and branch model based on the trunk and parameters mentioned above using the interactive parametric individual 3D tree modeling tool ParaTree. (3) Build a detailed 3D leaf model, as shown in Fig. 1 (a), using 3ds Max, a 3D modeling software. 
The leaf model is represented in triangular mesh, and each leaf consists of 10 triangles in our study. To reduce the computational complexity, the same 3D leaf model is applied to the entire tree, and then the 3D leaf models are added to the branches. The 3D model of the natural form peach tree is constructed as shown in Fig. 1 (c). (4) Modify the natural form model in ParaTree by editing branches and branch segments and then generate the 3D model of the open center form peach tree.

A number of local structural differences may be observed in the same tree canopy form. Therefore, two models of the open center form were produced from the same initial natural form model for comparison purposes. Model 1 of the open center form is created based on the model of the natural form, and it retains the four opening main branches and deletes all other branches (as shown in Fig. 2). Model 2 of the open center form is created based on the model of the natural form model as well; however, it retains three main branches, deletes one main branch with a smaller branching angle, and prunes all other branches retained in the first model. Fig. 2 shows the initial natural form model and two versions of open center models derived from the former.

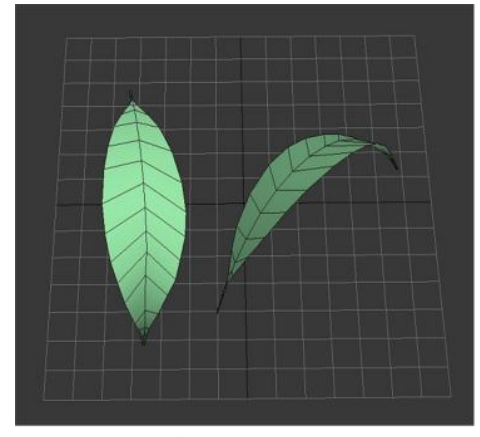

a

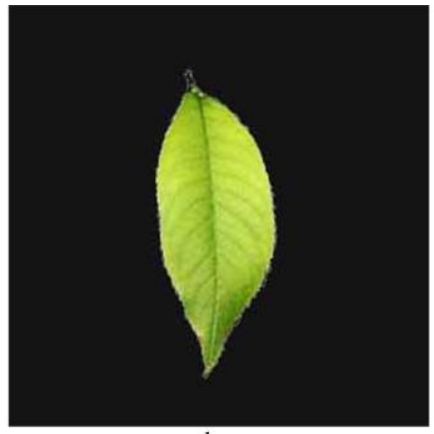

b

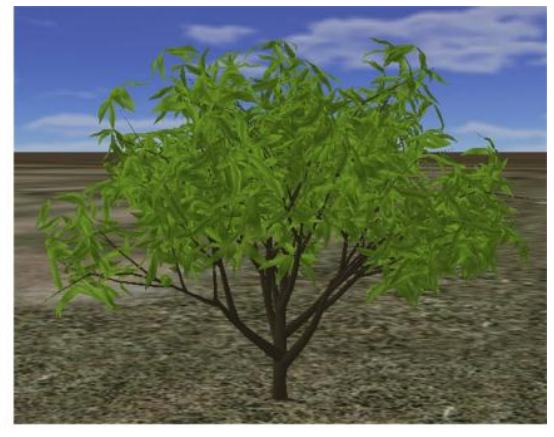

Fig. 1 Leaf model and individual natural form peach tree model: a: leaf model; b: leaf photograph; c: individual peach tree model

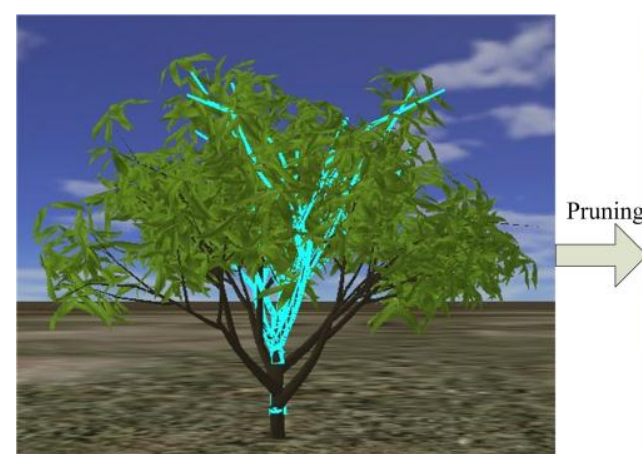

Natural form model 1

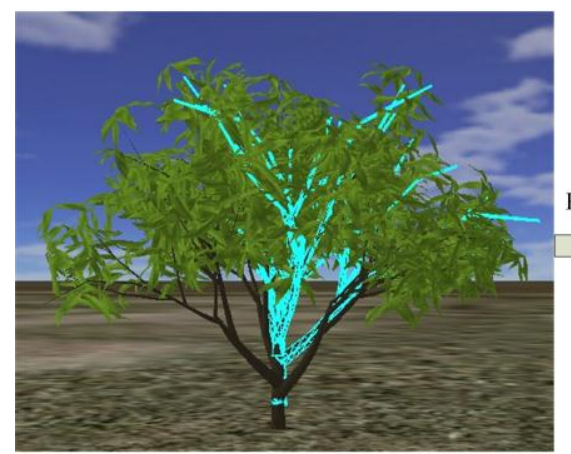

Natural form model 2

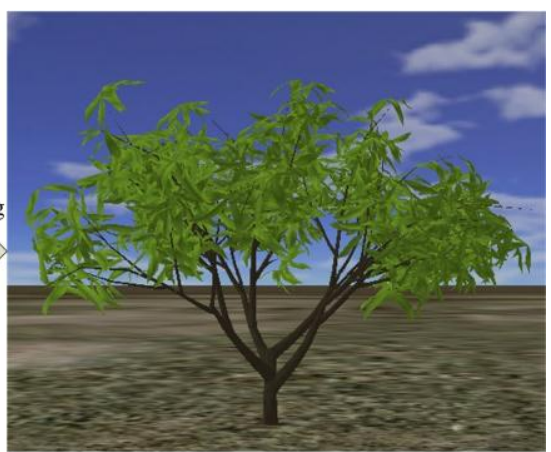

Open center form model 1

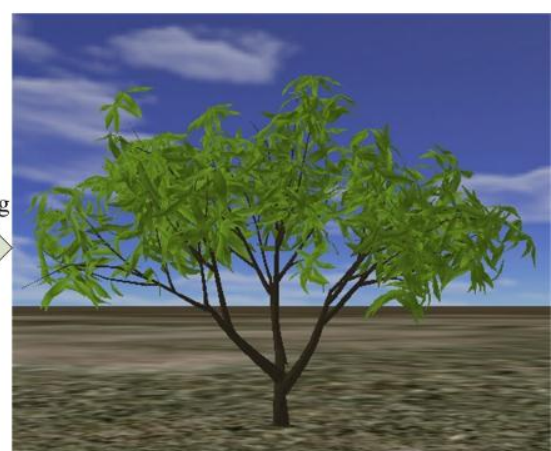

Open center form model 2 
Fig. 2. Schematic illustration of the modification process of different peach structure models. The branches highlighted in light blue were selected for pruning. The natural model form height is 2.13 $\mathrm{m}$. The average crown width is $2.45 \mathrm{~m}$, and the total area of all leaves for the entire model is 20.84 $\mathrm{m}^{2}$. The number of leaf triangles is 39305 . The open center form model 1 height is $2.00 \mathrm{~m}$, the average crown width is $2.3 \mathrm{~m}$, and the total area of leaves is $10.56 \mathrm{~m}^{2}$. The number of leaf triangles is 20077 . The open center form model 2 height is $1.97 \mathrm{~m}$. The average crown width is 2.2 $\mathrm{m}$, and the total area of all leaves for the entire model is $8.65 \mathrm{~m}^{2}$. The number of leaf triangles is 16417.

\subsection{Simulation of PAR distribution in a canopy}

Canopy photosynthesis can be calculated as the amount of light absorbed by the canopy and the leaf photosynthetic response to light(Spitters et al., 1986). Incident light consists of solar direct radiation and sky diffuse radiation. The photosynthetically active wave band is generally in the range of 400 to $700 \mathrm{~nm}$. Based on data from the literature, we assumed that PAR accounts for $40 \%$ of the global solar radiation energy.

Ray tracing and turtle algorithms were integrated into ParaTree; ray tracing is used to simulate direct solar radiation and turtle algorithms are used to simulate diffuse radiation. First, the light intensity in the field was calculated according to the geographical location using the atmospheric solar radiation transmission model. Then, the radiation transfer in the canopy was simulated to estimate the PAR for each leaf (or for each triangle). Consequently, the amount of total solar PAR intercepted by the entire tree per second and the average PAR photon flux density were calculated, and the values represent the average of the 12 PAR simulations in a day. We only considered the radiation used for photosynthesis by leaves, and radiation reaching the surface of the stem was only estimated to provide a visual expression of the light distribution in the canopy.

\subsubsection{PAR at the top of the canopy}

The only light sources considered were the sun and the sky, and light scattering from other organs was ignored. Because of changes in the position of the sun at different global locations, the PAR reaching the canopy is different at every moment of the year. Therefore, we comprehensively evaluated the light interception capacity of different canopy types with different solar zenith and azimuth angles. In the case study, all of the simulations were performed in Fuzhou on September 23, 2011 (fall equinox) under clear sky conditions. The study site is located at latitude $26^{\circ} 5$ ' $\mathrm{N}$ and longitude $119^{\circ} 18^{\prime} \mathrm{E}$. The intensity of the incoming radiation was calculated from 06:00 to 17:00 in one hour intervals repeated 12 times. The zenith and azimuth angles of the sun were calculated using the astronomical parametric algorithm(Wang, 1999) according to the latitude, day of the year, and time of day. The intensity of the direct solar PAR and diffuse sky PAR were calculated hourly using an atmospheric radiation transfer model (Liu and Jordan, 1960). Table 1 presents the results.

Table 1 Hourly PAR intensity at the top of canopy (23 Sep 2011)

\begin{tabular}{cccc}
\hline time & $\begin{array}{c}\text { Intensity of direct PAR } \\
\left(\mu \mathrm{mol} \cdot \mathrm{m}^{-2} \cdot \mathrm{s}^{-1}\right)\end{array}$ & $\begin{array}{c}\text { Intensity of diffuse PAR } \\
\left(\mu \mathrm{mol} \cdot \mathrm{m}^{-2} \cdot \mathrm{s}^{-1}\right)\end{array}$ & $\begin{array}{c}\text { Total intensity of PAR } \\
\left(\mu \mathrm{mol} \cdot \mathrm{m}^{-2} \cdot \mathrm{s}^{-1}\right)\end{array}$ \\
\hline 0600 & 2.6375 & 12.5162 & 15.1537 \\
\hline
\end{tabular}




\begin{tabular}{rrll}
\hline 07.00 & 2813750 & 863697 & 367.7447 \\
$08: 00$ & 728.2092 & 99.3342 & 827.5434 \\
09.00 & 11655689 & 93.794 & 1259.3483 \\
$10: 00$ & 1514.5694 & 84.5132 & 1599.0826 \\
11.00 & 1733.4339 & 77.4571 & 1810.891 \\
$12: 00$ & 1800.2210 & 75.1575 & 1875.3785 \\
$13: 00$ & 1708.6019 & 782938 & 1786.8957 \\
$14: 00$ & 1467.2816 & 85.9286 & 1553.2102 \\
$15: 00$ & 1100.907 & 95.1303 & 1196.038 \\
$16: 00$ & 655.3464 & 99.1275 & 754.4739 \\
17.00 & 219.2009 & 805257 & 299.7266 \\
\hline
\end{tabular}

\subsubsection{Spatial distribution of direct $P A R$}

A ray tracing algorithm was implemented for simulating the direct PAR distribution in the canopy. The algorithm was originally developed and integrated in the virtual plant software LSTree(Zou et al., 2011), in which the 3D plant geometric structure was described based on L-system. The simulation module for the PAR distribution was further integrated into ParaTree.

The ray tracing algorithm for calculating light distribution was implemented as follows. First, the reference projection plane and the number, direction and energy of the rays were defined. The direction of the rays is defined according to the zenith and azimuth angles of the sun, and the reference projection plane is perpendicular to the incident light and must be large enough so that rays originating from the plane can illuminate the entire canopy. The plane was first created as an infinite plane, and the direction is normally the same as the incoming light direction, and it is at a certain distance from the canopy surface. When the octree bounding box of the tree model was projected onto this infinite plane, eight vertex nodes were projected onto the plane (Fig. 3). The minimum parallelogram containing the eight points is regarded as the reference projection plane. The octree data structure was used to construct a hierarchical bounding box to improve the efficiency of the ray tracing algorithm by reducing unnecessary intersection calculations. In our approach, the number of rays affects the accuracy and efficiency of the algorithm. If the number of rays is insufficient, then the simulation errors will be large; however, if the number is too large, then the precision might not be adequate and the efficiency will be reduced. We performed a series of empirical simulations to analyze and compare the relationships among the number of rays, light interception and algorithm efficiency (Fig. 4). Based on the simulation results, we specified the number of rays at 1,000,000 and indicated a uniform distribution in the reference plane. The energy of each ray is calculated by dividing the total energy reaching the plane into 1,000,000 units. Given the starting point, direction and energy of each ray, the next step was to determine the triangle of canopy components that the ray intersects at the shortest distance from the starting point; once the triangle was found, the ray information was stored in the intersection list and intersecting triangle list. The ray information included the direction, starting location, intensity and intersections; thus, the energy reaching each organ surface (triangle) of the canopy can be recursively calculated. 


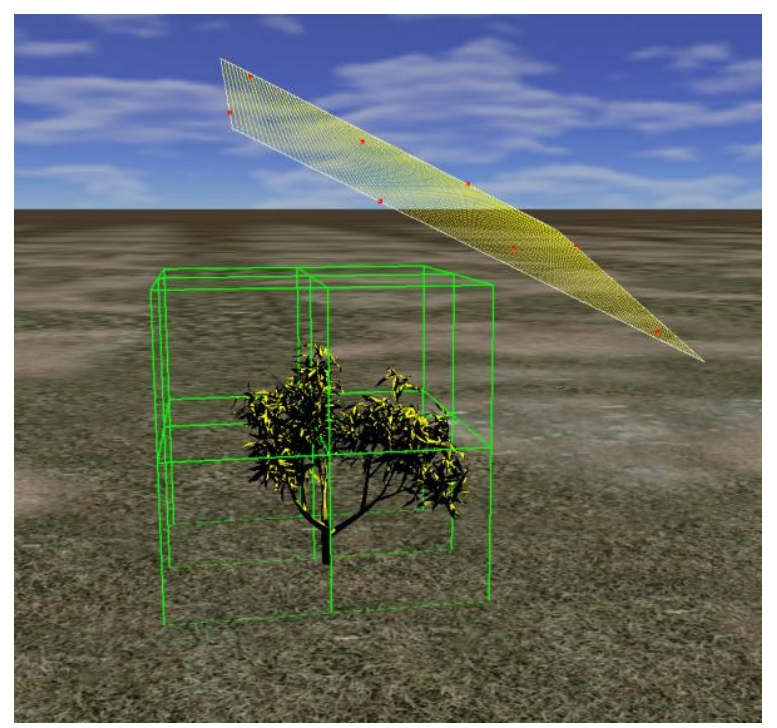

Fig. 3 Schematic diagram for the reference projection plane definition: eight red points on the plane are the projection of the octree bounding box onto the plane, and these points define the size of the plane
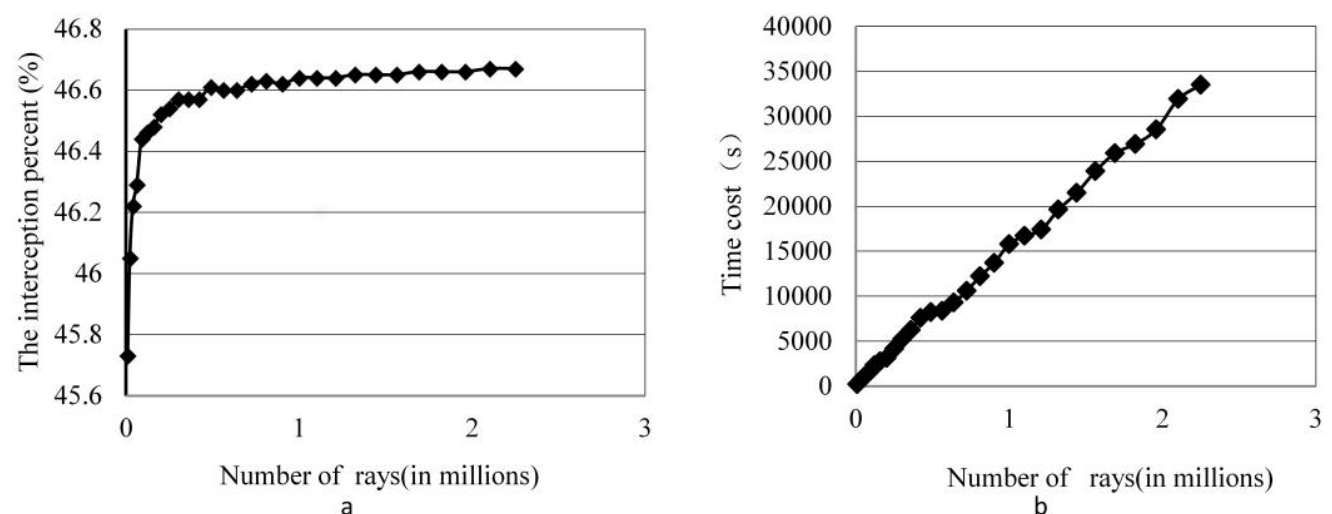

Fig. 4 Relationship among light interception, number of rays and algorithm efficiency: a: relationship between light interception efficiency and number of rays, with the percentage of light interception saturating approximately 1 million rays, b: relationship between algorithm efficiency and number of rays

\subsubsection{Spatial distribution of diffuse sky PAR}

Using the turtle algorithm(Dulk, 1989) for reference, simulations of the diffuse PAR distribution in canopy were implemented. For each element surface (triangle) of the canopy model, its center is regarded as the center of the overhead sky hemisphere (Fig. 5). The hemisphere is large enough to encompass all of the canopy above the given element. The surface of the sky hemisphere was divided into $N$ regions with equal solid angle sectors. The hemisphere is partitioned with the reference direction of the meridians and parallels. If the number of sectors is $N 1$ along the meridian direction and the number of sectors is $N 2$ along parallels direction, then $N$ is the product of $N 1$ and $N 2$. Our program records the center point of the region in a one dimensional array, and it uses another array to record the state of shading (false or true). False indicates that the region is shaded by other canopy components, and true indicates that the region 
is free of shading. If the ray from each region center intersects the projected element (triangle), then the region is shaded by the projected element, and the region is not viewable. Otherwise, the region is viewable.

To improve the computational efficiency, we first calculated the zenith angles and azimuth angles of the three vertexes of a triangle projected on the hemisphere. Thus, the range of angles along the meridian and parallel direction can be defined. Given a triangular element, the coordinates of its vertex are $(x, y, z)$, and the zenith angle $(\alpha)$ and azimuth angle $(\beta)$ are calculated as follows:

$$
\begin{aligned}
& \alpha=\arcsin \left(\frac{z}{\sqrt{x^{2}+y^{2}+z^{2}}}\right) \\
& \beta=\arcsin \left(\frac{y}{\sqrt{x^{2}+y^{2}}}\right)
\end{aligned}
$$

From formula (2), $\beta \in[-90,90]$, and $\beta$ can be transformed to 0 to 360 degrees in accordance with the positive or negative values of $\mathrm{x}$ and $\mathrm{y}$. For the three vertices of each triangle, three pairs of $\alpha$ and $\beta$ can be obtained, and the maximum and minimum values of these angles are used as the search range for identifying viewable regions. This step greatly reduces the number of unnecessary calculations required for the light intersection analysis.

If the simulation indicates that there are $m$ shaded regions in the sky hemisphere for facet $i$ (triangle), then the viewable rate of the sky for unit $i$ is calculated as follows:

$$
D_{i}=(N-m) / N
$$

Therefore, the intensity of diffuse sky PAR reaching facet $i$ can be estimated as follows:

$$
P_{i}=P_{d i f} \times D_{i}
$$

where $\mathrm{P}_{\text {dif }}$ is the intensity of diffuse PAR.

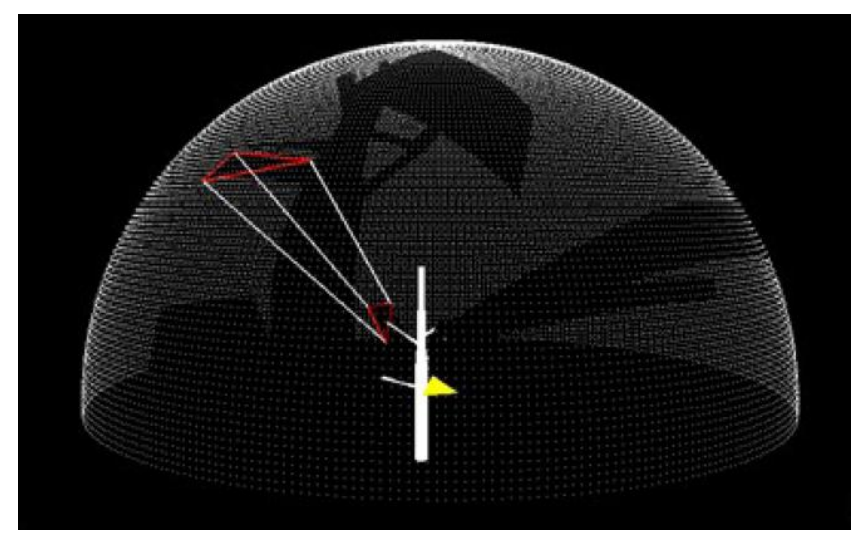

Fig. 5 Schematic diagram for calculating the sky viewable rate. The diffuse PAR that reaches the center of the yellow triangle will be calculated, the small red triangle is a shading component of the canopy, and the large red triangle refers to the projected area for the small red triangle on the hemisphere. The white points on the hemisphere are the centers of viewable solid angle sectors, and shaded areas are shown in black on the hemisphere. 
The scheme of subdividing the hemisphere affects the efficiency and simulation precision of the Turtle algorithm. We performed simulations to analyze and compare the relationships among the number of regions, light interception and algorithm efficiency. Consequently, the hemisphere is divided into $360 * 90$ solid angle sectors, which allows for optimal synthesis performance.

\subsection{Estimation of photosynthesis}

To evaluate the light interception efficiency, we calculated the net photosynthetic biomass per second $\left(P_{c}, \mu \mathrm{mol} \cdot \mathrm{s}^{-1}\right)$ of the entire canopy and the net photosynthetic rate per unit area $\left(P_{a}\right.$, $\left.\mu \mathrm{mol} \cdot \mathrm{m}^{-2} \cdot \mathrm{s}^{-1}\right)$.

The PAR intensity can be calculated at the leaf level (triangle). The net photosynthesis is calculated according to the model on the basis of absorbed PAR at leaf the level(Higgins et al., 1992). The leaf net photosynthetic rate is calculated as follows:

$$
p_{n}=\left(p_{\max }+D\right)\left[1-\exp \left(-Q I /\left(P_{\max }+D\right)\right)\right]-D
$$

where $P_{n}$ is net photosynthetic rate in units of $\mu \mathrm{mol} \cdot \mathrm{m}^{-2} \cdot \mathrm{s}^{-1}, I$ is the intensity of PAR, $P_{\operatorname{Max}}$ is the asymptotic maximum value of $P_{n}, Q$ is the initial slope of the index curve, and $D$ is the dark respiration rate. In this study, the parameters of the photosynthesis model (except PAR for peach) are from Higgins et al.(Higgins et al., 1992). The values of the relevant parameters are $P_{\operatorname{Max}}=$ $17.58 \mu \mathrm{mol} \cdot \mathrm{m}^{-2} \cdot \mathrm{s}^{-1}, Q=0.058$, and $D=2.205 \mu \mathrm{mol} \cdot \mathrm{m}^{-2} \cdot \mathrm{s}^{-1}$.

The biomass per leaf per second is calculated according to $P_{n}$ and by multiplying its intersecting area. Consequently, the net photosynthetic biomass of the entire canopy $\left(P_{c}\right.$, $\mu \mathrm{mol} \cdot \mathrm{s}^{-1}$ ) is calculated using formula 2 :

$$
P_{C}=\sum_{i=1}^{n} P_{n}\left(I_{i}\right) S_{i}
$$

where $P_{c}$ is the net photosynthetic biomass of the entire canopy, $n$ is the number of leaves (triangles) in the canopy, $P_{n}\left(I_{i}\right)$ is the net photosynthetic rate of leaf $i$ (triangle $i$ ), which can be calculated from formula 1 , and $S_{i}$ is the area of leaf $i$ (in $\mathrm{m}^{2}$ ). The average net photosynthesis per unit area is calculated according to formula 3 , in which $P_{c}$ is divided by the canopy area.

$$
p_{a}=\frac{p_{c}}{\sum_{i}^{n} s_{i}}
$$

where $P_{a}$ is the average net photosynthesis per unit area.

\subsection{Analysis of light interception}

Net photosynthesis reflects the light interception efficiency of the canopy. To analyze the light interception efficiency, we evaluated the net photosynthetic biomass per second $\left(P_{c}\right.$, $\left.\mu \mathrm{mol} \cdot \mathrm{s}^{-1}\right)$ of the entire canopy and the net photosynthetic rate per unit area $\left(P_{a}, \mu \mathrm{mol} \cdot \mathrm{m}^{-2} \cdot \mathrm{s}^{-1}\right)$. Photosynthesis models were integrated into ParaTree to calculate the net photosynthesis of the canopy. The analytical procedure for PAR interception capability is shown in Fig. 6. The 3D detailed canopy model is an important component of the simulation, which is constructed using 
the software ParaTree and 3ds Max according to section 2.1. Because stems do not provide a sufficiently large contribution to photosynthesis, the photosynthesis of the stems was not considered.

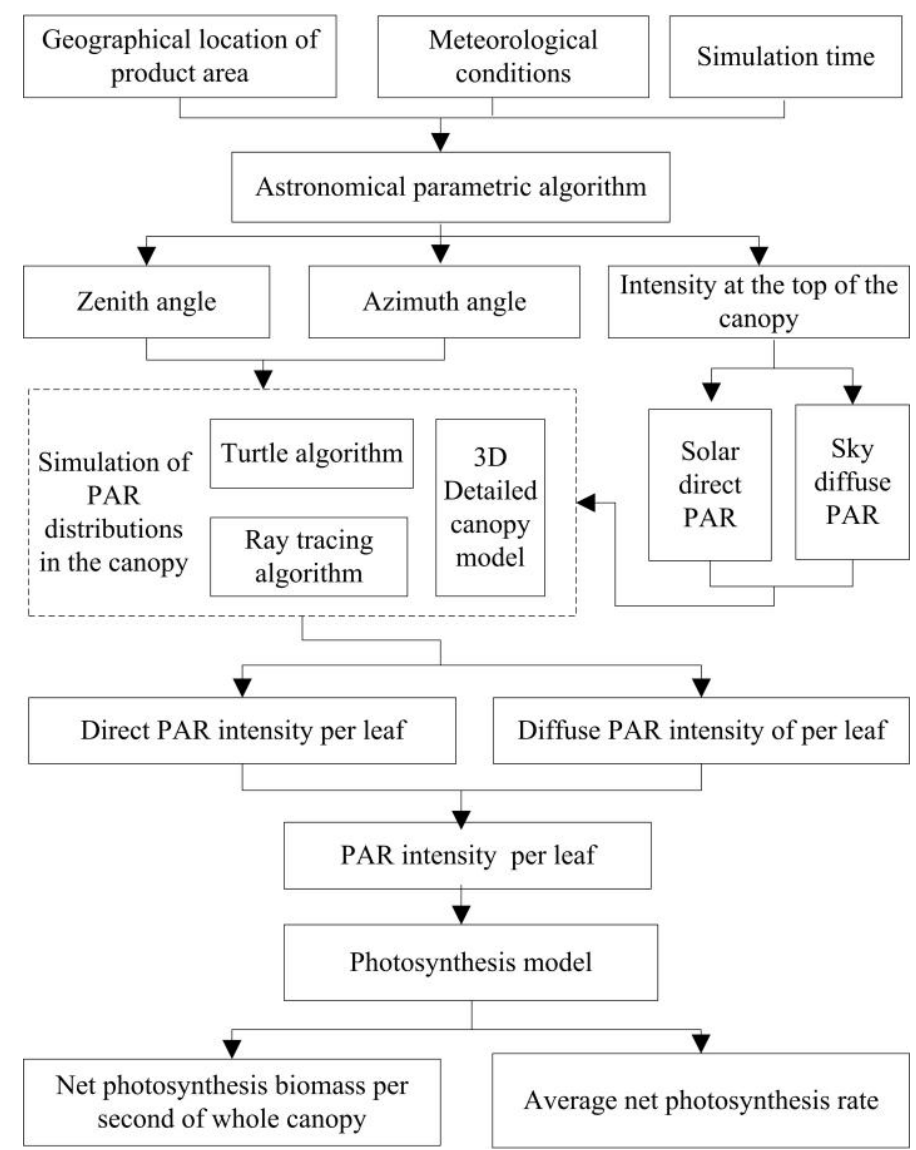

Fig. 6 Flow chart of the canopy light interception analysis

\section{Results and discussion}

\subsection{Light distribution in various types of canopy}

The light distribution, including the direct solar radiation and diffuse sky radiation, was simulated. We compared the PAR distribution in two different canopy forms: natural form and open center form. The leaf area was $20.84 \mathrm{~m}^{2}$ and $9.61 \mathrm{~m}^{2}$ for the natural form and open center form canopy models, respectively.

The distribution of direct solar PAR is shown in Fig. 7. The direct solar PAR intercepted by the entire canopy of the natural form and open center form was $2855.11 \mu \mathrm{mol} \cdot \mathrm{s}^{-1}$ and 1828.65 $\mu \mathrm{mol} \cdot \mathrm{s}^{-1}$, respectively, and the average intensity per leaf unit of direct PAR in the daytime of the natural form and open center form was $136.97 \mu \mathrm{mol} \cdot \mathrm{m}^{-2} \cdot \mathrm{s}^{-1}$ and $190.36 \mu \mathrm{mol} \cdot \mathrm{m}^{-2} \cdot \mathrm{s}^{-1}$, respectively. Because the natural form canopy model has more leaves relative to the open center form, it has a larger leaf area for intercepting solar PAR. The canopy of the natural form model intercepted more total direct PAR energy. However, leaves at the top of the canopy overshadowed the lower leaves, thus reducing the radiation transmission. Therefore, the average intensity per leaf unit of direct PAR in the natural form model was lower than that of the open center form model. 


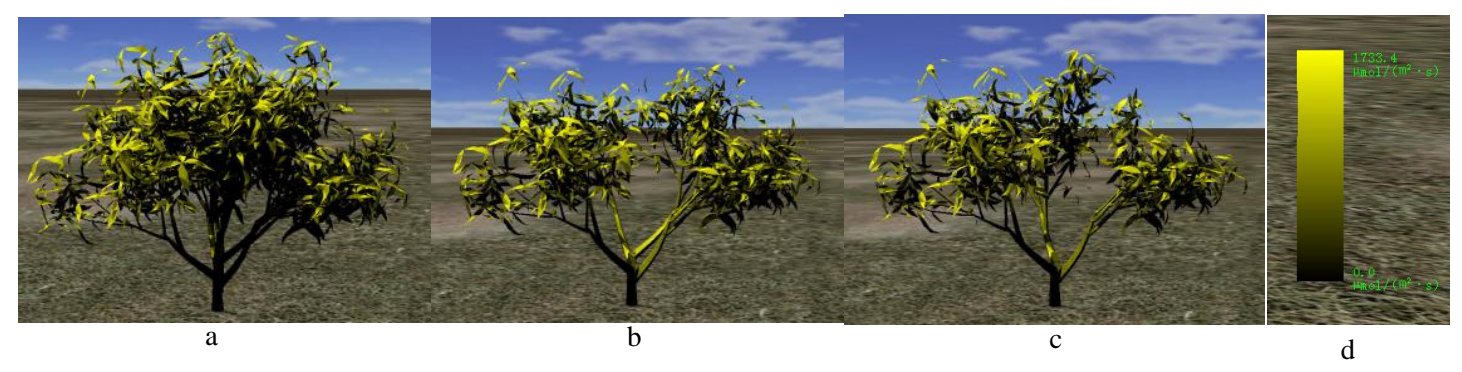

Fig. 7 Direct PAR distribution in different virtual peach canopies (at 11 o'clock). Bright colors represent stronger radiation intensity, whereas dark areas represent locations where the radiation intensity is weak. a: Natural form; b: open center form 1; c: open center form 2, d: color scale bar for radiation intensity. $\mathrm{a}, \mathrm{b}$ and $\mathrm{c}$ are rendered according to this scale.

The diffuse sky PAR distribution is shown in Fig. 8. In general, the pattern of diffuse PAR distribution in the canopy of two tree forms is similar to the pattern of direct solar PAR distribution. The diffuse PAR intercepted by the natural form model and open center form model was $383.69 \mu \mathrm{mol} \cdot \mathrm{s}^{-1}$ and $251.53 \mu \mathrm{mol} \cdot \mathrm{s}^{-1}$, respectively, and the average intensity of diffuse PAR in the daytime for the natural form model and open center form model was 18.41 $\mu \mathrm{mol} \cdot \mathrm{m}^{-2} \cdot \mathrm{s}^{-1}$ and $26.18 \mu \mathrm{mol} \cdot \mathrm{m}^{-2} \cdot \mathrm{s}^{-1}$, respectively. The natural form model has more leaves and a larger leaf area; thus, it intercepted more total diffuse PAR. However, the outside leaves shaded the inside leaves; therefore, the diffuse sky radiation coming from each direction could not illuminate the inside leaves, and the average intensity of the diffuse PAR intercepted by the natural form model was smaller.

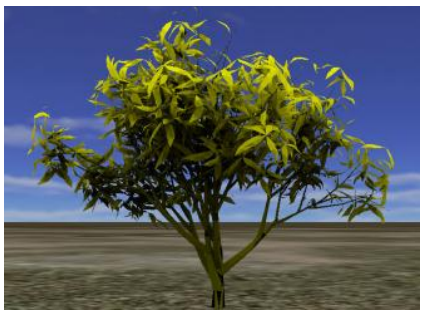

a

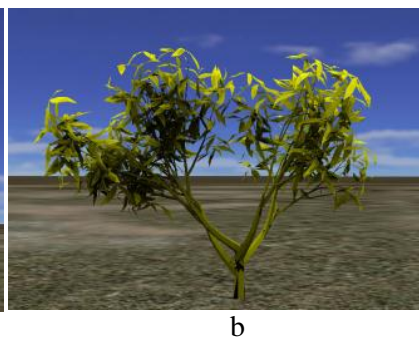

b

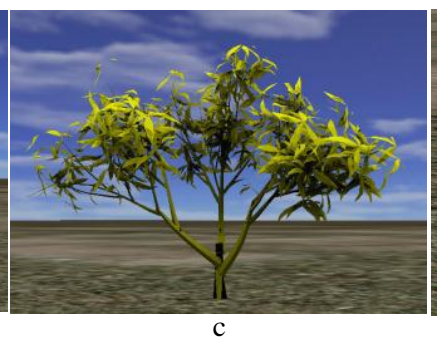

$\mathrm{c}$

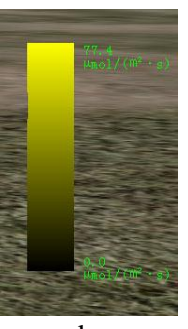

Fig. 8 Diffuse PAR distribution in different virtual peach canopy (at 11 o'clock). Bright colors represent stronger radiation intensity, whereas dark areas represent locations where the radiation intensity is weak. a: Natural form; b: open center form 1; c: open center form 2, d: color scale bar for radiation intensity. $\mathrm{a}, \mathrm{b}$ and $\mathrm{c}$ are rendered according to this scale.

Summing up the direct radiation distribution and sky diffuse radiation, we can estimate the average intensity of PAR for different tree canopy forms per day. The results are as follows: the instantaneous PAR intercepted by the natural form model and open center form model was $3238.80 \mu \mathrm{mol} \cdot \mathrm{s}^{-1}$ and $2080.19 \mu \mathrm{mol} \cdot \mathrm{s}^{-1}$, respectively, and the average intensity of PAR in the daytime for the natural form model and open center form model was $155.38 \mu \mathrm{mol} \cdot \mathrm{m}^{-2} \cdot \mathrm{s}^{-1}$ and $216.54 \mu \mathrm{mol} \cdot \mathrm{m}^{-2} \cdot \mathrm{s}^{-1}$, respectively. The leaf area of the natural form was larger and intercepted more PAR; however, the ineffective radiation area that was shaded by other canopy components was larger too. Thus, the average intensity of the PAR was smaller. The ineffective radiation area was specified as the area of the canopy where the total net photosynthesis was zero in the growth 
season(Gao et al., 2012).

Fig. 7 and Fig. 8 show that under clear sky conditions, the amount of direct solar PAR is much higher relative to the amount of diffuse PAR; however, the distribution of diffuse PAR was more uniform.

\subsection{Light interception efficiency}

The average net photosynthetic rate per unit area and the net photosynthetic biomass per second of the entire canopy were used to analyze the light interception of the canopy, and it is represented by the average of 12 simulation results per day. We analyzed the calculated photosynthesis of the two canopy forms, and the net photosynthetic biomass per second for the entire canopy of the natural form and open center form models was $43.16 \mu \mathrm{mol} \cdot \mathrm{s}^{-1}$ and 34.93 $\mu \mathrm{mol} \cdot \mathrm{s}^{-1}$, respectively, and the average net photosynthetic rate was $2.07 \mu \mathrm{mol} \cdot \mathrm{m}^{-2} \cdot \mathrm{s}^{-1}$ and 3.64 $\mu \mathrm{mol} \cdot \mathrm{m}^{-2} \cdot \mathrm{s}^{-1}$, respectively. These results are smaller than that of previous findings on peach trees(Genard et al., 2000), in which the photosynthesis rate varied from 5 to $15 \mu \mathrm{mol} \cdot \mathrm{m}^{-2} \cdot \mathrm{s}^{-1}$. The differences were most likely a result of simulation conditions because the incoming light intensity was larger compared with that of this study, and the lateral branches were assumed to be isolated; thus,i.e., they were not shadowed by any other object(Genard et al., 2000). In the research presented here, the simulation result most likely underestimated the light interception.

The average net photosynthetic rate at each hour is shown in Fig. 9. We observed that the net photosynthetic rate of different peach canopy forms was negative at 06:00, and the canopy respiration was stronger than the rate of photosynthesis. In addition, the net photosynthetic rate increased gradually, reaching maximum values at between 12:00 and 13:00 gradually decreased, the net photosynthetic rate of the natural form reaching negative values at 17:00.

In terms of the net photosynthetic biomass of the entire canopy during the daytime, although the value was higher for the natural form than for the open center form, the leaf area of the natural form was larger and the energy consumption for respiration was also higher at night. Thus, we can speculate that the natural form has a lower photosynthetic rate per unit area compared with the open center form for the entire daytime and nighttime. Therefore, the light interception capability of the open center form peach canopy is superior to the natural form. Proper pruning can help improve the interception capability of PAR radiation and the net photosynthetic rate per unit area of peach trees. 


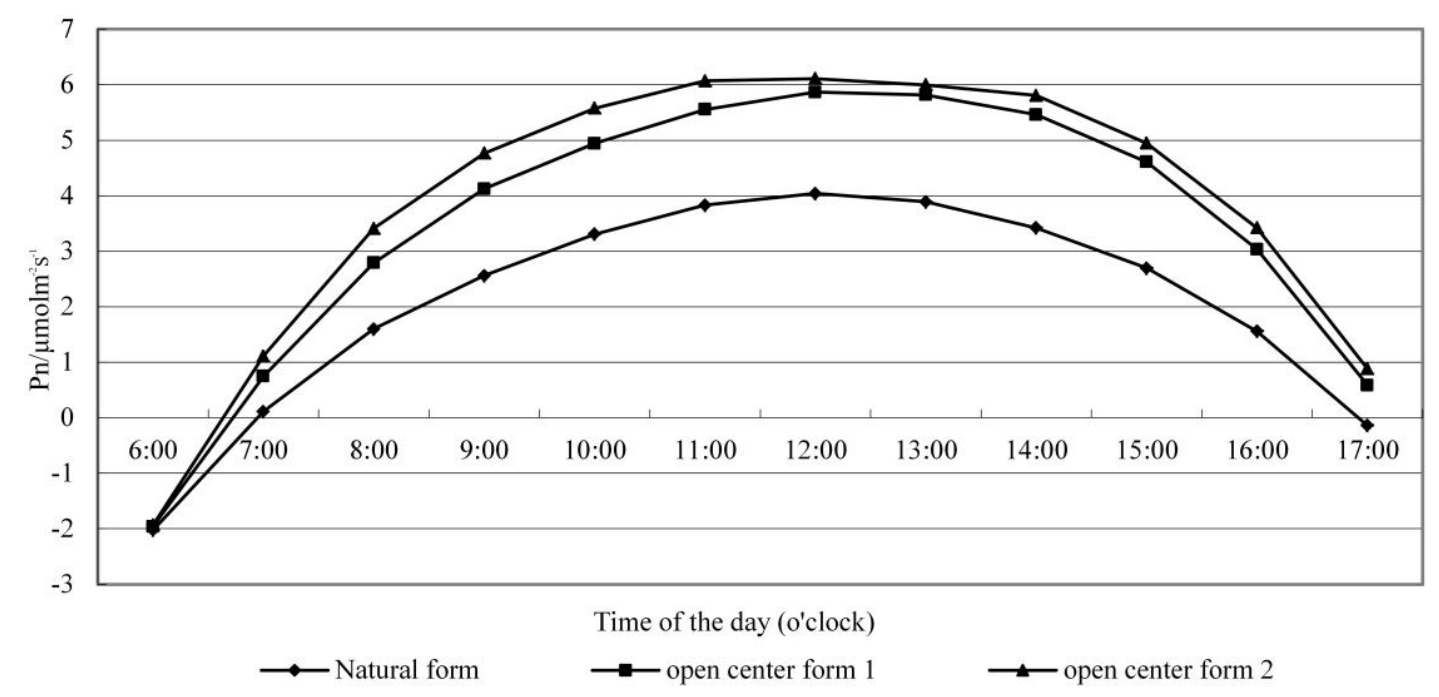

Fig. 9 Hourly variation of the simulated net photosynthesis rate per unit leaf area $\left(\mathrm{P}_{\mathrm{a}}\right)$ for the three types of peach canopy form

The analysis results observed here are similar to those of Wang et al.(2001). Accounting for light penetration and ventilation, the open center form is superior to the natural form because the light interception capability is stronger and the light distribution in the canopy is more uniform, which is conducive to absorbing PAR and improves the quality of fruit. The open center form has been widely applied peach cultivation and extended to different fruit trees(Wang and Yang, 2001). Consequently, the analysis results are reasonable, and the quantitative analysis approach is adaptive to analyzing light interception efficiency and designing canopy forms.

\section{Conclusions}

This study is based on a 3D canopy structure representation method with the aim of developing an approach and tool for performing quantitative analysis of tree canopy light interception and exploring optimal fruit tree canopy forms that produce high yields and high quality. Through a number of pruning training runs, long-term field observations and experience, a number of effective tree architecture forms, such as open center forms, spindle forms, central leader forms and Y forms, have been discovered and applied widely for cultivation; however, few analysis methodologies are capable of explaining and quantifying the efficiency of different tree canopy forms. Canopy light interception is a fundamental factor that contributes to horticultural crop performance and quality(Zhang et al., 2012). Therefore, we propose a quantitative analysis approach based on a 3D tree architectural modeling method (virtual plant). The virtual plant method can accurately represent tree topology structures and the geometry and position of organs. Tree organs can be represented with small 3D units according to the user requirements. Moreover, the light interception of each unit can be calculated and the radiation transfer and interception among the units can be simulated.

ParaTree was integrated with a ray tracing algorithm, turtle algorithm and photosynthesis model. Ray tracing is used for simulating direct solar radiation, and the turtle algorithm is used for simulating diffuse radiation. Using peach tree canopies with a natural form and open center form 
as examples, we constructed detailed 3D architectural models and simulated the radiation distribution in the canopy via 3D visualization. Visualizing simulated data is extremely important for increasing the accessibility of research results to the end user(Parrott, 2011). The PAR intensity per leaf (triangle) was calculated, and the net photosynthetic rate of the canopy forms was estimated. The results show that the open center form is less effective in terms of the net photosynthetic biomass per second for the entire canopy, whereas it is more efficient in terms of the net photosynthetic rate during the daytime. The natural form model has a larger leaf area; thus, the energy consumption for respiration is higher at night. A comparison of the light interception estimates of the two types of peach canopy forms indicates that the open center form is more adaptive for cultivation. The analysis results are similar to those of Wang et al.(2001). The analysis of the peach canopy types demonstrates that our approach of analyzing light interception is a potentially useful tool for designing ideotypes and popularizing fruit pruning techniques. ParaTree provides functions for 3D tree architectural modeling, model pruning (editing) and light interception analysis. Our approach can be applied to every individual leaf unit that is distinguishable in the 3D model at every time step, which allows users to assess the light interception of the canopy under different management scenarios via virtual 3D visual models. We believe that this approach is a time-saving and cost-efficient alternative for complement expensive and tedious field experiments.

\section{Acknowledgements}

This work was supported by the "863" Hi-Tech Research and Development Program of China (Grant No. 2012AA102002) and a program of the National Science Foundation of China (Grant No. 41471334, Grant No. 31200430). The authors would also like to thank the other members of our work group.

\section{References}

Allen, M., Prusinkiewicz, P., Favreau, R., DeJong, T., 2007. L-PEACH, an L-systems based model for simulating architecture, carbohydrate source-sink interactions and physiological responses of growing trees. Frontis 22, 139-150.

Annandale, J., Jovanovic, N., Campbell, G., Du Sautoy, N., Lobit, P., 2004. Two-dimensional solar radiation interception model for hedgerow fruit trees. Agr Forest Meteorol 121, 207-225.

Barillot, R., Louarn, G., Escobar-Gutiérrez, A.J., Huynh, P., Combes, D., 2011. How good is the turbid medium-based approach for accounting for light partitioning in contrasted grass-legume intercropping systems? Ann Bot-london 108, 1013-1024.

Buck-Sorlin, G., De Visser, P.H., Henke, M., Sarlikioti, V., Van Der Heijden, G.W., Marcelis, L.F., Vos, J., 2011. Towards a functional-structural plant model of cut-rose: simulation of light environment, light absorption, photosynthesis and interference with the plant structure. Ann Bot-london 108, 1121-1134.

Cieslak, M., Lemieux, C., Hanan, J., Prusinkiewicz, P., 2008. Quasi-Monte Carlo simulation of the light environment of plants. Funct Plant Biol 35, 837-849.

Da Silva, D., Han, L., Costes, E., 2014. Light interception efficiency of apple trees: a multiscale computational study based on MappleT. Ecol Model 290, 45-53.

Dulk, J.A.d., 1989. The interpretation of remote sensing: a feasibility study. Landbouwuniversiteit te Wageningen.

Génard, M., Baret, F., Simon, D., 2000. A 3D peach canopy model used to evaluate the effect of tree 
architecture and density on photosynthesis at a range of scales. Ecol Model 128, 197-209.

Gao, Q.H., Ye, Z.W., Zhang, Z., LI, S.C., Wu, Y.L., Su, M.S., 2006. Effects of different training systems on the light interception ability and fruiting of young nectarine trees in greenhouse. Scientia Agricultura Sinica 39, 1294-1298.

Gao, Z.Q., Feng, S.Z., Zhang, X.C., Chen, J.J., 2012. The simulation of leaf net photosynthtic rates in different radiation in apple canopy. Acta Ecol. Sin. 32, 1037-1044.

Han, L., Costes, E., Boudon, F., Cokelaer, T., Pradal, C., Da Silva, D., Faivre, R., 2012. Investigating the influence of geometrical traits on light interception efficiency of apple trees: a modelling study with MAppleT, Plant Growth Modeling, Simulation, Visualization and Applications (PMA), 2012 IEEE Fourth International Symposium on. IEEE, pp. 152-159.

Higgins, S., Larsen, F., Bendel, R., Radamaker, G., Bassman, J., Bidlake, W., Al Wir, A., 1992. Comparative gas exchange characteristics of potted, glasshouse-grown almond, apple, fig, grape, olive, peach and Asian pear. Sci Hortic-amsterdam 52, 313-329.

Iio, A., Kakubari, Y., Mizunaga, H., 2011. A three-dimensional light transfer model based on the vertical point-quadrant method and Monte-Carlo simulation in a Fagus crenata forest canopy on Mount Naeba in Japan. Agr Forest Meteorol 151, 461-479.

Lin, D., Chen, C.C., Tang, L.Y., Zou, J., Wang, Q.M., 2011. Interactive pruning operation on virtual tree base on color encoding. Journal of Computer-Aided Design \& Computer Graphics 11, 1799-1807.

Lin, R.K., Zou, J., Chen, C.C., Tang, L.Y., Lin, D., 2012. Interactive editing technique and its implementation for virtual tree structure. Transactions of the CSAE28, 175-180.

Liu, B.Y., Jordan, R.C., 1960. The interrelationship and characteristic distribution of direct, diffuse and total solar radiation. Sol Energy 4, 1-19.

Mirás-Avalos, J.M., Egea, G., Nicolás, E., Génard, M., Vercambre, G., Moitrier, N., Valsesia, P., González-Real, M.M., Bussi, C., Lescourret, F., 2011. QualiTree, a virtual fruit tree to study the management of fruit quality. II. Parameterisation for peach, analysis of growth-related processes and agronomic scenarios. Trees 25, 785-799.

Parrott, L., 2011. Hybrid modelling of complex ecological systems for decision support: Recent successes and future perspectives. Ecol Inform 6, 44-49.

Rakocevic, M., Sinoquet, H., Christophe, A., Varlet-Grancher, C., 2000. Assessing the geometric structure of a white clover (Trifolium repens L.) canopy using 3-D digitising. Ann Bot-london, 519-526.

Sarlikioti, V., De Visser, P., Marcelis, L., 2011. Exploring the spatial distribution of light interception and photosynthesis of canopies by means of a functional-structural plant model. Ann Bot-london 107, 875-883.

Sonohat, G., Sinoquet, H., Kulandaivelu, V., Combes, D., Lescourret, F., 2006. Three-dimensional reconstruction of partially 3D-digitized peach tree canopies. Tree Physiol 26, 337-351.

Spitters, C., Toussaint, H., Goudriaan, J., 1986. Separating the diffuse and direct component of global radiation and its implications for modeling canopy photosynthesis Part I. Components of incoming radiation. Agr Forest Meteorol 38, 217-229.

Su, Z.B., Zhan, S.Y., Zheng, P., Li, X.M., Zhang, J.C., 2008. Method for digital design of crop plant type with high photosynthetic efficiency. Transactions of the CSAE 24, 203-207.

Tang, L.Y., Chen, C.C., Zou, J., Lin, Y.X., Lin, D., Li, J.G., 2011. OntoPlant: an integrated virtual plant software package for different scale applications, Spatial Data Mining and Geographical 
Knowledge Services (ICSDM), 2011 IEEE International Conference on. IEEE, pp. 308-314.

Tang, L.Y., Lin, D., Huang, H.Y., Zou, J., Chen, C.C., Du, Y.H., 2012. Growth simulation of young Chinese fir based on virtual plant. Journal of Geo-Information Science 5, 569-575.

Vos, J., Evers, J.B., Buck-Sorlin, G., Andrieu, B., Chelle, M., De Visser, P.H., 2009. Functional-structural plant modelling: a new versatile tool in crop science. J Exp Bot, erp345.

Wang, A.Z., Zhang, F.F., Han, M.Y., Tian, H.C., Tian, Y.M., Zhao, C.P., 2009. Effects of the central leader tree form on the light interception ability, fruit yield and quality of peach. Journal of Fruit Science 1, 86-89.

Wang, B.Z., 1999. Calculation of astronomical parameters in solar energy. Sol Energy 2, 8-10.

Wang, Y.J., Yang, X.P., 2001. Study on tree from structure and light energy utilization of facilities fruit tree. J. Shanxi Agric. Univ 21, 200-202.

Willaume, M., Lauri, P.-É., Sinoquet, H., 2004. Light interception in apple trees influenced by canopy architecture manipulation. Trees 18, 705-713.

Zhang, J.J., Luo, R.L., Patrick, S., Matthew, W., Zhang, Q., 2012. Canopy architecture affects light interception in sweet cherry your. American Society of Agricultural and Biological Engineers Annul International Meeting, pp:1511-1521.

Zou, J., Lin, Y.X., Chen, C.C., Tang, L.Y., 2011. Modelling the 3D distribution of photosynthetically active radiation of direct solar radiation based on virtual plant canopy. J.FuzhouUniv.Nat.Sci. 39, 838-844.

\section{List of table1}

Table 1 Hourly PAR intensity at the top of canopy (23 Sep 2011)

\section{List of figures}

Fig. 1 Leaf model and individual natural form peach tree model: a: leaf model; b: leaf photograph; c: individual peach tree model

Fig. 2. Schematic illustration of the modification process of different peach structure models. The branches highlighted in light blue were selected for pruning. The natural model form height is 2.13 $\mathrm{m}$. The average crown width is $2.45 \mathrm{~m}$, and the total area of all leaves for the entire model is 20.84 $\mathrm{m}^{2}$. The number of leaf triangles is 39305. The open center form model 1 height is $2.00 \mathrm{~m}$, the average crown width is $2.3 \mathrm{~m}$, and the total area of leaves is $10.56 \mathrm{~m}^{2}$. The number of leaf triangles is 20077 . The open center form model 2 height is $1.97 \mathrm{~m}$. The average crown width is 2.2 $\mathrm{m}$, and the total area of all leaves for the entire model is $8.65 \mathrm{~m}^{2}$. The number of leaf triangles is 16417.

Fig. 3 Schematic diagram for the reference projection plane definition: eight red points on the plane are the projection of the octree bounding box onto the plane, and these points define the size of the plane

Fig. 4 Relationship among light interception, number of rays and algorithm efficiency: a: relationship between light interception efficiency and number of rays, with the percentage of light interception saturating approximately 1 million rays, b: relationship between algorithm efficiency and number of rays 
Fig. 5 Schematic diagram for calculating the sky viewable rate. The diffuse PAR that reaches the center of the yellow triangle will be calculated, t. The small red triangle is a shading component of the canopy, and the large red triangle refers to the projected area for the small red triangle on the hemisphere. The white points on the hemisphere are the centers of viewable solid angle sectors, and shaded areas are shown in black on the hemisphere.

Fig. 6 Flow chart of the canopy light interception analysis

Fig. 7 Direct PAR distribution in different virtual peach canopies (at 11 o'clock). Bright colors represent stronger radiation intensity, whereas dark areas represent locations where the radiation intensity is weak. a: Natural form; b: open center form 1; c: open center form 2; d: color scale bar for radiation intensity. $\mathrm{a}, \mathrm{b}$ and $\mathrm{c}$ are rendered according to this scale.

Fig. 8 Diffuse PAR distribution in different virtual peach canopy (at 11 o'clock). Bright colors represent stronger radiation intensity, whereas dark areas represent locations where the radiation intensity is weak. a: Natural form; b: open center form 1; c: open center form 2, d: color scale bar for radiation intensity. $\mathrm{a}, \mathrm{b}$ and $\mathrm{c}$ are rendered according to this scale.

Fig. 9 Hourly variation of the simulated net photosynthesis rate per unit leaf area $\left(\mathrm{P}_{\mathrm{a}}\right)$ for the three types of peach canopy form 